\title{
Fidaxomicin vs Vancomycin for the Treatment of a First Episode of Clostridium Difficile Infection: A Meta-analysis and Systematic Review
}

\author{
Laith A. Al Momani ${ }^{1}$, Omar Abughanimeh ${ }^{2}$, Boonphiphop Boonpheng ${ }^{1}$, Joseph Gabriel Gabriel ${ }^{1}$, Mark
} Young 3

1. Department of Internal Medicine, East Tennessee State University, Johnson City, USA 2. Department of Internal Medicine, University of Missouri Kansas City School of Medicine, Kansas City, USA 3. Department of Gastroenterology, East Tennessee State University, Johnson City, USA

Corresponding author: Omar Abughanimeh, omarabughanimeh@yahoo.com

\begin{abstract}
Clostridium difficile infection (CDI) continues to possess a significant disease burden in the United States (US) as well as all over the world. Given the increase in severity and recurrence rate, the decrease in cure rate, and the fact that the virulent ribotype 027 strain remains one of the most commonly identified strains in the US, the Infectious Diseases Society of America (IDSA) published a clinical practice guideline in February 2018 moving away from metronidazole as the first-line treatment for initial CDI and recommending either oral vancomycin or fidaxomicin. The aim of this study is to evaluate the clinical data available comparing the efficacy of primary treatment of CDI between those two antibiotics. We performed a PubMed, PubMed Central, and ScienceDirect database search without restriction to regions, publication types, or languages. A comprehensive literature search was performed from January 1, 1980 up to March 20, 2018. We used the following keywords in different combinations: Clostridium difficile, Clostridium difficile infection, CDI, C. diff, C. difficile, fidaxomicin, vancomycin, pseudomembranous colitis, and antibiotic-associated colitis. The search was limited to human studies. Data were independently extracted by two reviewers with disagreements resolved by a third author. We pooled an odds ratio (OR) on two primary outcomes: Clinical cure rate and rate of recurrence during the follow-up period. The computer search was also supplemented with manual searches by the authors of the retrieved review articles and primary studies. The search phrase "((Clostridium difficile) AND vancomycin) AND fidaxomicin" had the highest yield results. We identified four observational studies with a total of 2,303 patients with CDI that met our inclusion criteria. Compared with vancomycin, fidaxomicin use was associated with a significantly lower recurrence of CDI with a pooled OR of 0.47 (95\% confidence interval (CI), $0.37-0.60, \mathrm{I} 2=0$ ). On the other hand, there was no significant association of fidaxomicin use with CDI cure rate compared to vancomycin with a pooled OR of 1.22 ( $95 \% \mathrm{CI}$, $0.93-1.60$, I2 = 0). In light of the recently updated clinical practice guidelines by the IDSA, our review suggests that fidaxomicin has a more sustained clinical response with a statistically significant lower recurrence rate. Although fidaxomicin appears to be the better drug with statistical significance, its costeffectiveness continues to be an ongoing controversy. More randomized clinical trials are needed to shed light on this matter to assess if there is any clinical significance in fidaxomicin superiority.
\end{abstract}

Received 05/29/2018

Review began 06/02/2018 Review ended 06/09/2018 Published 06/11/2018

๑) Copyright 2018

Al Momani et al. This is an open access article distributed under the terms of the Creative Commons Attribution License CC-BY 3.0., which permits unrestricted use, distribution, and reproduction in any medium, provided the original author and source are credited.
Categories: Internal Medicine, Gastroenterology, Infectious Disease

Keywords: clostridium difficile, treatment of clostridium difficile, vancomycin, fidaxomicin, c. diff, c. difficile

\section{Introduction And Background}

Clostridium difficile infection (CDI) continues to possess a significant disease burden in both the United States (US) and globally. There have been a reported 453,000 infections in 2011 in the US alone, with 83,000 of those experiencing at least one recurrence and 29,000 expiring within 30 days of the initial diagnosis [1]. The incidence and severity of CDI continue to trend upwards, with a reported increase in communityacquired infections of a disease that was once considered nosocomial and antibiotic-related [2-4]. A similar trend is reported in children [5-6].

Due to its severity and high rates of recurrence, lower cure rates, and ribotype 027 virulence in the US, the Infectious Diseases Society of America (IDSA) published clinical practice guidelines in February 2018 moving away from metronidazole as the first-line treatment for initial CDI and recommending, with a strong level of evidence, either oral vancomycin or oral fidaxomicin [7].

The purpose of this systematic review and meta-analysis is to analyze the available data on the comparison of oral vancomycin and oral fidaxomicin as the first-line medication treatment of CDI. The reader must bear in mind that multiple studies have attempted to prove that although fidaxomicin is more costly than the alternatives, it may prove to be the more cost-effective option.

\section{Review}




\section{Methods}

Search Strategy and Selection Criteria

We performed a PubMed, PubMed Central, and ScienceDirect database search without restriction to regions, publication types, or languages. A comprehensive literature search was performed from inception to March 20, 2018, during which time the IDSA guidelines update on changing the initial drug of choice to oral vancomycin or fidaxomicin has been set forth. The following keywords were used in different combinations: Clostridium difficile, Clostridium difficile infection, CDI, C. diff, C. difficile, fidaxomicin, vancomycin, pseudomembranous colitis, and antibiotic-associated colitis. The search was limited to human studies. The computer search was supplemented with manual searches by the authors of the retrieved review articles and primary studies. The search phrase ((Clostridium difficile) AND vancomycin) AND fidaxomicin had the highest yield results.

\section{Data Extraction and Quality Assessment}

Studies were included if they met the following: 1) used a well-defined case-control or cohort design and 2) presented an odds ratio (OR) for our main outcome with a 95\% confidence interval (CI) or reported sufficient data to calculate these parameters. Exclusion criteria were: 1 ) case reports, case series, and review articles and 2) insufficient information concerning evaluation rates. Two authors screened all abstracts independently obtained from the initial literature search and removed those not fulfilling the inclusion criteria. The data were abstracted from all included studies into a standardized table. A third investigator reviewed the data for accuracy prior to the data query. The inclusion/exclusion decisions were made after consultation with the other authors.

Outcome Definition

In comparing the efficacy of treatment of initial CDI with vancomycin versus fidaxomicin, two endpoints were used: 1) achieving clinical cure with a resolution of symptoms without the need for further treatment and 2) recurrence of infection during the follow-up period, which was at least three weeks and up to four weeks following a 10-day course of antibiotics. This included relapse and reinfection. An overall OR was used for both of these endpoints.

Statistical Analysis

All statistical analyses were performed using the Comprehensive Meta-Analysis (CMA), Version 3 software (BioStat, Inc., Eaglewood, NJ). The pooled risk ratios of Clostridium difficile cure and recurrence in patients treated with fidaxomicin in comparison to those treated with vancomycin were calculated using the generic inverse method of DerSimonian and Laird [8]. A random effect model was used, given the high likelihood of between-study variance due to the difference in underlying population and methodology. Cochran's Q-test, which was supplemented by $\mathrm{I}^{2}$ statistic, was used to evaluate the statistical heterogeneity. This $\mathrm{I}^{2}$ statistic quantifies the proportion of the total variation across studies, that is, due to true heterogeneity rather than chance. A value of $\mathrm{I}^{2}$ of $0 \%$ to $25 \%$ denotes trivial heterogeneity, greater than $25 \%$ but $\leqslant 50 \%$ denotes low heterogeneity, greater than $50 \%$ but $\leqslant 75 \%$ denotes moderate heterogeneity, and greater than $75 \%$ represents high heterogeneity [9].

\section{Results}

Search Results

The initial search yielded 267 citations, all of which underwent title and abstract review. The majority of them were excluded at this step, including those that were case reports, letters to editor, review articles, or interventional studies. A total of 45 studies underwent full-length article review, and 41 of them were excluded as they did not include controls, did not report the outcome of interest, or were review articles. Therefore, a total of four studies [10-13] met our inclusion criteria and were included in the meta-analysis. Figure 1 outlines our search methodology and selection process. Baseline characteristics of the included studies are summarized in Table 1 . 


\section{Cureus}

Records identified through database searching that
underwent abstract review
( $n=267)$

1. Not relevant studies $(n=144)$

-2. Letters to outhors $(n=2)$

-3. Cose reports/series $(n=76)$

Screened records underwent full-length article review [n=45]

1. Did not include controls/report

outcome of interest $(n=35$

Studies included in

-2. Review articles $(n=6)$

FIGURE 1: A flow diagram demonstrates the search methodology and selection process for this meta-analysis

n: number 


\section{Cureus}

\begin{tabular}{|c|c|c|c|c|}
\hline & $\begin{array}{l}\text { Louie et al. } \\
\text { [12] }\end{array}$ & Cornely et al. [13] & Loui et al. [10] & $\begin{array}{l}\text { Houseman et al. } \\
\text { [11] }\end{array}$ \\
\hline Country & $\begin{array}{l}\text { US and } \\
\text { Canada }\end{array}$ & $\begin{array}{l}\text { US, Canada, France, } \\
\text { Spain, Belgium, } \\
\text { Germany, UK, Italy, } \\
\text { Sweden }\end{array}$ & $\begin{array}{l}\text { US, Canada, France, Spain, } \\
\text { Belgium,Germany, UK, Italy, Sweden }\end{array}$ & US \\
\hline Study design & Clinical trial & Clinical trial & Clinical trial & Clinical trial \\
\hline Year & 2011 & 2012 & 2013 & 2016 \\
\hline $\begin{array}{l}\text { Number of participants } \\
\text { enrolled }\end{array}$ & 629 & 535 & 1,105 & 34 \\
\hline $\begin{array}{l}\text { Number of participants } \\
\text { enrolled/Fidaxomicin }\end{array}$ & 302 & 271 & 539 & 18 \\
\hline $\begin{array}{l}\text { Number of participants } \\
\text { enrolled/Vancomycin }\end{array}$ & 327 & 264 & 566 & 16 \\
\hline $\begin{array}{l}\text { Overall participants } \\
\text { analyzed }\end{array}$ & 596 & 509 & 794 & 24 \\
\hline $\begin{array}{l}\text { Overall participants } \\
\text { analyzed/Fidaxomicin }\end{array}$ & 287 & 253 & 391 & 12 \\
\hline $\begin{array}{l}\text { Overall participants } \\
\text { analayzed/Vancomycin }\end{array}$ & 309 & 256 & 403 & 12 \\
\hline $\begin{array}{l}\text { Mean age of } \\
\text { participants in years }\end{array}$ & 61.9 & 63.4 & Fidaxomicin: 63.3 Vancomycin: 62.3 & $\begin{array}{l}\text { Fidaxomicin: } 69 \\
\text { Vancomycin: } 66\end{array}$ \\
\hline $\begin{array}{l}\text { Median follow up } \\
\text { duration }\end{array}$ & 21 days & 21 days & 21 days & 28 days \\
\hline $\begin{array}{l}\text { OR: Cure rate, } \\
\text { Fidaxomicin vs } \\
\text { Vancomycin }\end{array}$ & $\begin{array}{l}1.24(0.77- \\
2.00)\end{array}$ & $1.09(0.65-1.83)$ & $1.24(0.8-1.92)$ & $2.5(0.46-13.52)$ \\
\hline $\begin{array}{l}\text { OR: Recurrence rate, } \\
\text { Fidaxomicin vs } \\
\text { Vancomycin }\end{array}$ & $\begin{array}{l}0.54(0.35- \\
0.84)\end{array}$ & $0.39(0.24-0.64)$ & $0.46(0.32-0.67)$ & $0.85(0.1-7.04)$ \\
\hline $\begin{array}{l}\text { Confounder } \\
\text { adjustment }\end{array}$ & $\begin{array}{l}\text { Age, Sex, } \\
\text { Inpatient } \\
\text { status, NAP1 } \\
\text { strain }\end{array}$ & $\begin{array}{l}\text { Age, Sex, Inpatient } \\
\text { status, NAP1 strain }\end{array}$ & $\begin{array}{l}\text { Age, Sex, Inpatient status, NAP1 strain, } \\
\text { BMI, WBC, serum albumin, serum } \\
\text { creatinine, concomitant antibiotic therapy }\end{array}$ & $\begin{array}{l}\text { Age, Sex, } \\
\text { Community } \\
\text { acquired CDI, } \\
\text { NAPI strain }\end{array}$ \\
\hline $\begin{array}{l}\text { Quality assessment } \\
\text { (Newcastle-Ottawa } \\
\text { scale) }\end{array}$ & Good & Good & Good & Good \\
\hline
\end{tabular}

\section{TABLE 1: Total Studies Utilized in This Meta-analysis}

BMI: body mass index; CDI: Clostridium difficile infection; NAP1: North American pulsed-field gel electrophoresis type 1; OR: odds ratio; UK: United Kingdom; US: United States; WBC: white blood cells

\section{Meta-analysis results}

Recurrence Rate

Four observational studies with a total of 2,303 patient with CDI were enrolled. Compared with vancomycin, fidaxomicin use was associated with a significantly lower recurrence with a pooled OR of 0.47 (95\% CI, 0.37 $0.60, \mathrm{I} 2=0$ ) (Figure 2). 


\section{Cureus}

\begin{tabular}{|c|c|c|c|c|c|c|}
\hline \multirow[t]{2}{*}{ Study name } & \multirow[t]{2}{*}{ Outcome } & \multirow[b]{2}{*}{$\begin{array}{l}\text { Odds } \\
\text { ratio }\end{array}$} & \multicolumn{4}{|c|}{ Statistics for each study } \\
\hline & & & $\begin{array}{c}\text { Lower } \\
\text { limit }\end{array}$ & $\begin{array}{c}\text { Upper } \\
\text { limit }\end{array}$ & Z-Value & p-Value \\
\hline Louie et al. 2011 & Recurrence & 0.54 & 0.35 & 0.84 & -2.76 & 0.01 \\
\hline Cornely et al. 2012 & Recurrence & 0.39 & 0.24 & 0.64 & -3.70 & 0.00 \\
\hline Louie et al. 2013 & Recurrence & 0.46 & 0.32 & 0.67 & -4.12 & 0.00 \\
\hline \multirow[t]{2}{*}{ Housman et al. 2016} & Recurrence & 0.85 & 0.10 & 7.04 & -0.15 & 0.88 \\
\hline & & 0.47 & 0.37 & 0.60 & -6.09 & 0.00 \\
\hline
\end{tabular}

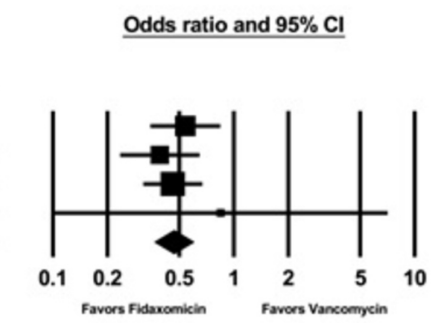

FIGURE 2: Recurrence rate

Cl: confidence interval

Cure Rate

There was no significant association of fidaxomicin use with CDI cure rate compared to vancomycin with a pooled OR of 1.22 (95\% CI, $0.93-1.60$, I2 = 0) (Figure 3).

\begin{tabular}{lcrrrrrr} 
Study name & Outcome & \multicolumn{6}{c}{ Statistics for each study } \\
\cline { 3 - 6 } & & $\begin{array}{c}\text { Odds } \\
\text { ratio }\end{array}$ & $\begin{array}{c}\text { Lower } \\
\text { limit }\end{array}$ & $\begin{array}{c}\text { Upper } \\
\text { limit }\end{array}$ & Z-Value & p-Value \\
Louie et al. 2011 & Cure & 1.24 & 0.77 & 2.00 & 0.88 & 0.38 \\
Cornely et al. 2012 & Cure & 1.09 & 0.65 & 1.83 & 0.33 & 0.74 \\
Louie et al. 2013 & Cure & 1.24 & 0.80 & 1.92 & 0.96 & 0.34 \\
Housman et al. 2016 Cure & 2.50 & 0.46 & 13.52 & 1.06 & 0.29 \\
& & 1.22 & 0.93 & 1.60 & 1.44 & 0.15
\end{tabular}

Odds ratio and $95 \% \mathrm{Cl}$

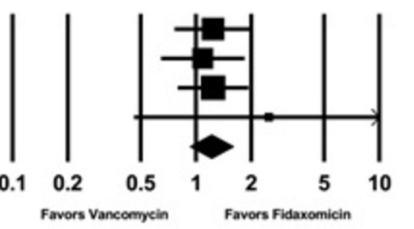

FIGURE 3: Cure rate

Cl: confidence interval

Evaluation for Publication Bias

The funnel plots evaluating recurrence and cure rate are shown in Figures 4-5. They are symmetric and do not suggest the presence of publication bias in favor of a positive study for all of the outcomes. In addition, Egger's regression asymmetry test showed no evidence of publication bias ( $\mathrm{P}>0.05$ for both outcomes).

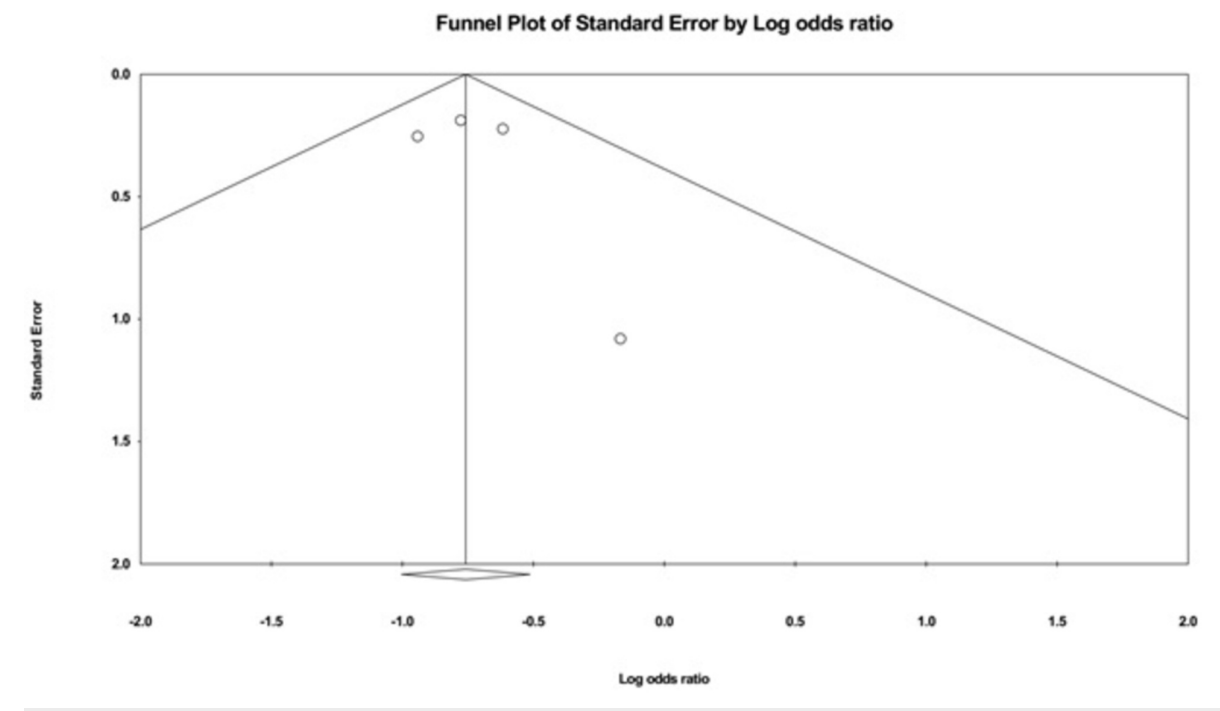

FIGURE 4: A funnel plot: recurrence rate 


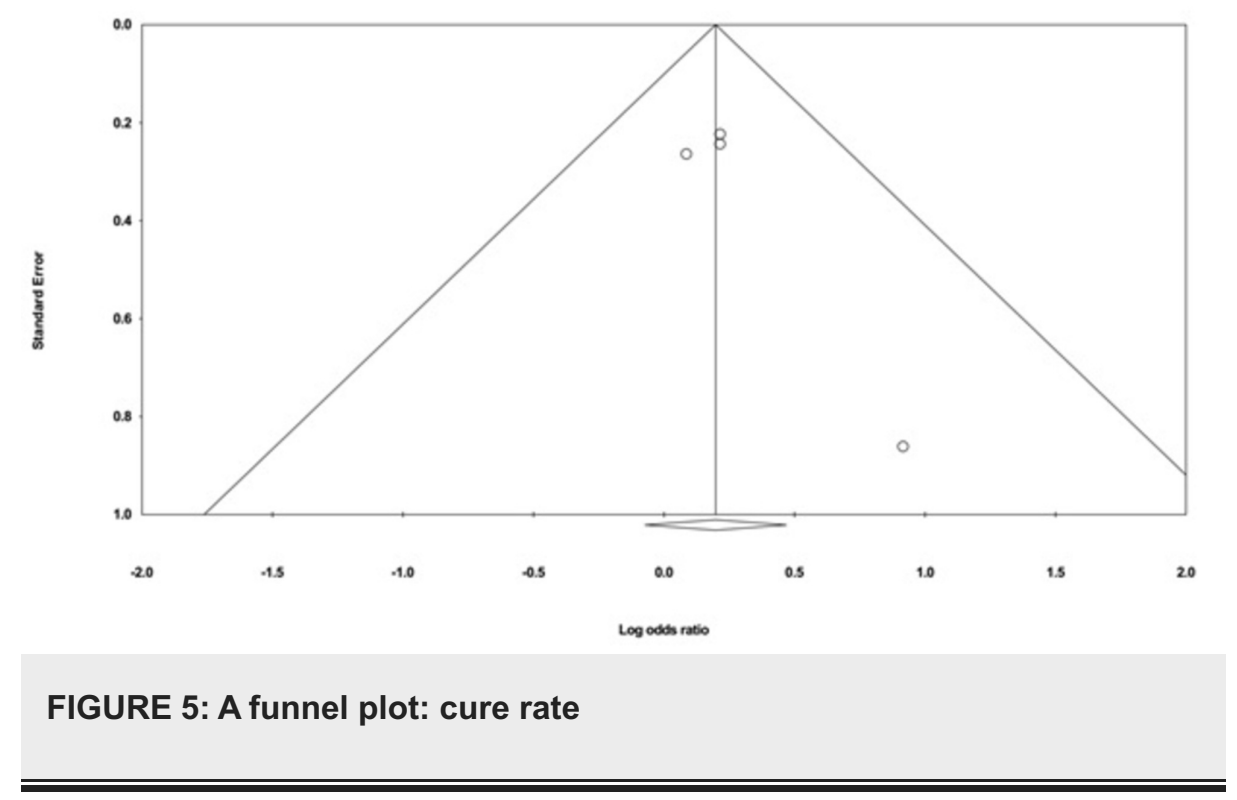

Sensitivity Analysis

Sensitivity analysis was performed by excluding one study at a time to investigate the effect of each study on the pooled odds ratio for each outcome assessed. The pooled effect estimate from this sensitivity analysis remained essentially unchanged.

\section{Discussion}

The studies we used in our meta-analysis included patients with their first episode of CDI. All of these patients had clinical symptoms suggestive of CDI, including a minimum of three episodes of unformed stool in a 24-hour period with no known or documented the prior diagnosis of CDI. The diagnosis was made by a positive C. difficile polymerase chain reaction test or toxin A, B, C assay, depending on the specific study criteria. These patients were then randomized for treatment with vancomycin, $124 \mathrm{mg}$ orally four times daily, or fidaxomicin, $200 \mathrm{mg}$ orally twice a day, for a total of 10 days. These patients were followed up for a minimum of three weeks and up to four weeks after completion of their antibiotic course.

In our review and meta-analysis of two endpoints (cure rate or the rate of symptoms' resolution and the recurrence of symptoms within the follow-up period), we can show that the use of fidaxomicin was associated with a statistically significant lower recurrence. However, there was no significant difference with the cure rate when compared with that of vancomycin.

Fidaxomicin is the first macrolide antibacterial agent approved for the treatment of CDI [14]. It inhibits transcription by binding to the deoxyribonucleic acid (DNA)-template ribonucleic acid (RNA) polymerase sigma subunit and hence, prevents the initial separation of the bacterial DNA strands. Essentially, it inhibits the initiation of RNA synthesis very early on in that pathway [15-16]. This unique mechanism of action might explain fidaxomicin's very narrow spectrum of antimicrobial coverage at low concentrations [17-19].

Multiple studies have shown fidaxomicin to have a substantially higher in vitro activity against C. difficile compared to vancomycin [20-23] with a more prolonged post-antibiotic effect [24]. Furthermore, fidaxomicin is a bactericidal drug, whereas vancomycin is bacteriostatic [25]. Fidaxomicin's lower rates of relapse following treatment might be attributed to the fact that it causes fewer changes to the bowel microbiota of C. difficile-infected patients compared to vancomycin both during [26-27] and after treatment [28]. Fidaxomicin also has a narrower antimicrobial coverage [17], and unlike vancomycin, it inhibits sporulation. As Louie et al. [29] showed, patients treated with fidaxomicin had a $2.3 \log 10$ lower fecal spore counts at $21-28$ days post-therapy compared to a patient treated with vancomycin. Similar results were reported by Housman et al. years later [11]. This might at least suggest that fidaxomicin might be a better first-line option for patients at a higher risk of recurrence, like older patients or patients with cancer [10]. It is worth noting here that a study by Nerandzic et al. in 2012 showed that fidaxomicin reduced acquisition and overgrowth of vancomycin-resistant enterococci and Candida species in CDI patients compared to vancomycin [30].

Similar to vancomycin, fidaxomicin demonstrates minimal systemic absorption, which explains why the most common side effects are gastrointestinal in nature, like nausea and abdominal pain, both of which are likely to be part of CDI symptomatology [31-33]. This characteristic makes it a very well-tolerated drug in 
Whenever fidaxomicin is compared with vancomycin, the cost is always an examined variable. A 10-day course has at least three times more acquisition cost than that of vancomycin [38]. However, multiple studies in high-income countries have shown the cost-effectiveness of fidaxomicin [39-41]. A recent systemic review by Burton et al. in 2017 also showed that fidaxomicin was, in fact, more cost-effective than vancomycin [42]. Prior to that, Stranges et al. performed a cost-utility analysis in the US in 2013 which showed an incremental cost-effectiveness ratio of \$67,576/quality adjusted life-year (QALY) confirming the results of Sclar et al. in 2012, who also showed potential cost-effectiveness in the US health system [43-44]. Furthermore, a study with regards to hospital cost savings in 2015 showed that their hospital saved \$3,047 USD (United States dollars) per patient treated with fidaxomicin compared to a patient treated with vancomycin [45]. Similar promising results were seen in patients with cancer and patients with renal impairment $[41,46]$. This postulated cost-effectiveness might be explained by the decreased recurrence rate and hence, hospital readmissions that fidaxomicin provides, both of which, in addition to the length of stay, have not been well compared.

On the other hand, other studies have shown conflicting results. Reveles et al. found similar total costs comparing the two drugs [47]. Another systemic review by Le et al. in 2018 concluded that the costeffectiveness of fidaxomicin compared to vancomycin was not definitive [48]. Costs will vary between healthcare systems as well; an increase in cost with the use of fidaxomicin has been suggested in the Canadian health care system [49].

All in all, this calls for research and strong randomized control trials to assess the cost-effectiveness of fidaxomicin compared to vancomycin in the US.

\section{Conclusions}

In light of the recently updated clinical practice guidelines by the IDSA for the treatment of C. difficile infection, we set out to compare both of the recommended first-line drugs, vancomycin and fidaxomicin. Our meta-analysis found a similar cure rate; however, fidaxomicin was found to have a more sustained clinical response with a statistically significant lower recurrence rate. Although fidaxomicin appears to be the better drug with statistical significance, its cost-effectiveness continues to be an ongoing controversy. More randomized clinical trials are needed to shed light on this matter to assess if there is any clinical significance in fidaxomicin superiority, particularly as CDI incidence, severity, and recurrence rates continue to be on an upward trajectory.

\section{Additional Information \\ Disclosures}

Conflicts of interest: In compliance with the ICMJE uniform disclosure form, all authors declare the following: Payment/services info: All authors have declared that no financial support was received from any organization for the submitted work. Financial relationships: All authors have declared that they have no financial relationships at present or within the previous three years with any organizations that might have an interest in the submitted work. Intellectual property info: This work has been submitted to the American College of Gastroenterology Conference 2018 in abstract form. This manuscript is not previously published or currently under consideration for publication elsewhere and, if accepted, will not be published elsewhere without written consent of the publisher. Other relationships: All authors have declared that there are no other relationships or activities that could appear to have influenced the submitted work.

\section{References}

1. Lessa FC, Mu Y, Bamberg WM, et al.: Burden of Clostridium difficile infection in the United States . N Engl I Med. 2015, 372:825-34. 10.1056/NEJMc1505190

2. Freeman J, Bauer MP, Baines SD, et al.: The changing epidemiology of Clostridium difficile infections. Clin Microbiol Rev. 2010, 23:529-49. 10.1128/CMR.00082-09

3. Chitnis AS, Holzbauer SM, Belflower RM, et al.: Epidemiology of community-associated Clostridium difficile infection, 2009 through 2011. JAMA Intern Med. 2013, 173:1359-67. 10.1001/jamainternmed.2013.7056

4. Khanna S, Pardi DS, Aronson SL, et al.: The epidemiology of community-acquired Clostridium difficile infection: a population-based study. Am J Gastroenterol. 2012, 107:89-95. 10.1038/ajg.2011.398

5. Khanna S, Baddour LM, Huskins WC, et al.: The epidemiology of Clostridium difficile infection in children: a population-based study. Clin Infect Dis. 2013, 56:1401-406. 10.1093/cid/cit075

6. Benson L, Song X, Campos J, Singh N: Changing epidemiology of Clostridium difficile-associated disease in children. Infect Control Hosp Epidemiol. 2007, 28:1233-35. 10.1086/520732

7. McDonald LC, Gerding DN, Johnson S, et al.: Clinical practice guidelines for Clostridium difficile infection in adults and children: 2017 update by the Infectious Diseases Society of America (IDSA) and Society for Healthcare Epidemiology of America (SHEA). Clin Infect Dis. 2018, 66:e1-e48. 10.1093/cid/cix1085

8. DerSimonian R, Laird N: Meta-analysis in clinical trials. Control Clin Trials. 1986, 7:177-88. 10.1016/01972456(86)90046-2

9. Higgins JP, Thompson SG, Deeks JJ, et al.: Measuring inconsistency in meta-analyses. BMJ. 2003, 327:55760. 10.1136/bmj.327.7414.557 
10. Louie TJ, Miller MA, Crook DW, et al.: Effect of age on treatment outcomes in Clostridium difficile infection . J Am Geriatr Soc. 2013, 61:222-30. 10.1111/jgs.12090

11. Housman ST, Thabit AK, Kuti JL, et al.: Assessment of Clostridium difficile burden in patients over time with first episode infection following fidaxomicin or vancomycin. Infect Control Hosp Epidemiol. 2016, 37:215-18. 10.1017/ice.2015.270

12. Louie TJ, Miller MA, Mullane KM, et al.: Fidaxomicin versus vancomycin for Clostridium difficile infection. N Engl J Med. 2011, 364:422-31. 10.1056/NEJMoa0910812

13. Cornely OA, Crook DW, Esposito R, et al.: Fidaxomicin versus vancomycin for infection with Clostridium difficile in Europe, Canada, and the USA: a double-blind, non inferiority, randomised controlled trial. Lancet Infect Dis. 2012, 12:281-89. 10.1016/S1473-3099(11)70374-7

14. Johnson AP: Drug evaluation OPT-80, a narrow-spectrum macrocyclic antibiotic . Curr Opin Investig Drugs. 2007, 8:168-73.

15. Artsimovitch I, Seddon J, Sears P: Fidaxomicin is an inhibitor of the initiation of bacterial RNA synthesis . Clin Infect Dis. 2012, 55:S127-31. 10.1093/cid/cis358

16. Osburne MS, Sonenshein AL: Inhibition by lipiarmycin of bacteriophage growth in Bacillus subtilis . J Virol. 1980, 33:945-53.

17. Zhanel GG, Walkty AJ, Karlowsky JA: Fidaxomicin A novel agent for the treatment of Clostridium difficile infection. Can J Infect Dis Med Microbiol. 2015, 26:305-12. 10.1155/2015/934594

18. Goldstein EJ, Babakhani F, Citron DM: Antimicrobial activities of fidaxomicin . Clin Infect Dis. 2012, 55:S143-48. 10.1093/cid/cis339

19. Gerber M, Ackermann G: OPT-80 a macrocyclic antimicrobial agent for the treatment of Clostridium difficile infections: a review. Expert Opin Investig Drugs. 2008, 17:547-53. 10.1517/13543784.17.4.547

20. Karlowsky JA, Laing NM, Zhanel GG: In vitro activity of OPT-80 tested against clinical isolates of toxinproducing Clostridium difficile. Antimicrob Agents Chemother. 2008, 52:4163-65. 10.1128/AAC.00476-08

21. Ackermann G, Löffler B, Adler D, Rodloff AC: In vitro activity of OPT-80 against Clostridium difficile . Antimicrob Agents Chemother. 2004, 48:2280-82. 10.1128/AAC.48.6.2280-2282.2004

22. Credito KL, Appelbaum PC: Activity of OPT-80, a novel macrocycle, compared with those of eight other agents against selected anaerobic species. Antimicrob Agents Chemother. 2004, 48:4430-34. 10.1128/AAC.48.11.4430-4434.2004

23. Babakhani F, Seddon J, Robert N, et al.: Effects of inoculum, $\mathrm{pH}$, and cations on the in vitro activity of fidaxomicin (OPT-80, PAR-101) against Clostridium difficile. Antimicrob Agents Chemother. 2010, 54:267476. 10.1128/AAC.01842-09

24. Babakhani F, Gomez A, Robert N, et al.: Postantibiotic effect of fidaxomicin and its major metabolite, OP1118, against Clostridium difficile. Antimicrob Agents Chemother. 2011, 55:4427-29. 10.1128/AAC.0010411

25. Babakhani F, Gomez A, Robert N, Sears P: Killing kinetics of fidaxomicin and its major metabolite, OP1118, against Clostridium difficile. J Med Microbiol. 2011, 60:1213-17. 10.1099/jmm.0.029470-0

26. Tannock GW, Munro K, Taylor C, et al.: A new macrocyclic antibiotic, fidaxomicin (OPT-80), causes less alteration to the bowel microbiota of Clostridium difficile-infected patients than does vancomycin. Microbiology. 2010, 156:3354-59. 10.1099/mic.0.042010-0

27. Chilton CH, Crowther GS, Freeman J, et al.: Successful treatment of simulated Clostridium difficile infection in a human gut model by fidaxomicin first line and after vancomycin or metronidazole failure. J Antimicrob Chemother. 2014, 69:451-62. 10.1093/jac/dkt347

28. Louie TJ, Cannon K, Byrne B, et al.: Fidaxomicin preserves the intestinal microbiome during and after treatment of Clostridium difficile infection (CDI) and reduces both toxin reexpression and recurrence of CDI. Clin Infect Dis. 2012, 55:S132-42. 10.1093/cid/cis338

29. Louie T, Miller M, Donskey C, et al.: Clinical outcomes safety, and pharmacokinetics of OPT-80 in a phase 2 trial with patients with Clostridium difficile infection. Antimicrob Agents Chemother. 2009, 53:223-28. 10.1128/AAC.01442-07

30. Nerandzic MM, Mullane K, Miller MA, et al.: Reduced acquisition and overgrowth of vancomycin-resistant enterococci and Candida species in patients treated with fidaxomicin versus vancomycin for Clostridium difficile infection. Clin Infect Dis. 2012, 55:S121-26. 10.1093/cid/cis440

31. Sears P, Crook DW, Louie TJ, et al.: Fidaxomicin attains high fecal concentrations with minimal plasma concentrations following oral administration in patients with Clostridium difficile infection. Clin Infect Dis. 2012, 55:S116-20. 10.1093/cid/cis337

32. Oshima H, Yamazaki T, Benner L, et al.: Comparison of the safety, tolerability, and pharmacokinetics of fidaxomicin in healthy Japanese and Caucasian subjects. Clin Drug Investig. 2015, 35:375-84. 10.1007/s40261-015-0291-9

33. Fehér C, Múñez Rubio E, Merino Amador P, et al.: The efficacy of fidaxomicin in the treatment of Clostridium difficile infection in a real-world clinical setting: a Spanish multi-centre retrospective cohort. Eur J Clin Microbiol Infect Dis. 2017, 36:295-303. 10.1007/s10096-016-2802-X

34. Golan Y, Epstein L: Safety and efficacy of fidaxomicin in the treatment of Clostridium difficile-associated diarrhea. Therap Adv Gastroenterol. 2012, 5:395-402. 10.1177/1756283X12461294

35. Chen LF, Anderson DJ: Efficacy and safety of fidaxomicin compared with oral vancomycin for the treatment of adults with Clostridium difficile-associated diarrhea: data from the OPT-80-003 and OPT-80-004 studies. Future Microbiol. 2012, 7:677-83. 10.2217/fmb.12.44

36. Miller M: Fidaxomicin (OPT-80) for the treatment of Clostridium difficile infection. Expert Opin Pharmacother. 2010, 11:1569-78. 10.1517/14656566.2010.485614

37. O'Gorman MA, Michaels MG, Kaplan SL, et al.: Safety and pharmacokinetic study of fidaxomicin in children with Clostridium difficile-associated diarrhea: a phase 2a multicenter clinical trial. J Pediatric Infect Dis Soc. 2017, (Epub ahead of print):10.1093/jpids/pix037

38. Cruz MP: Fidaxomicin (Dificid), a novel oral macrocyclic antibacterial agent for the treatment of Clostridium difficile-associated diarrhea in adults. P T. 2012, 37:278-81.

39. Nathwani D, Cornely OA, Van Engen AK, et al.: Cost-effectiveness analysis of fidaxomicin versus 
vancomycin in Clostridium difficile infection. J Antimicrob Chemother. 2014, 69:2901-12.

10.1093/jac/dku257

40. Watt M, Dinh A, Le Monnier A, Tilleul P: Cost-effectiveness analysis on the use of fidaxomicin and vancomycin to treat Clostridium difficile infection in France. J Med Econ. 2017, 20:678-86.

10.1080/13696998.2017.1302946

41. Watt M, McCrea C, Johal S, et al.: A cost-effectiveness and budget impact analysis of first-line fidaxomicin for patients with Clostridium difficile infection (CDI) in Germany. Infection. 2016, 44:599-606. 10.1007/s15010-016-0894-y

42. Burton HE, Mitchell SA, Watt M: A systematic literature review of economic evaluations of antibiotic treatments for Clostridium difficile infection. Pharmacoeconomics. 2017, 35:1123-40. 10.1007/s40273-0170540-2

43. Stranges PM, Hutton DW, Collins CD: Cost-effectiveness analysis evaluating fidaxomicin versus oral vancomycin for the treatment of Clostridium difficile infection in the United States. Value Health. 2013, 16:297-304. 10.1016/j.jval.2012.11.004

44. Sclar DA, Robison LM, Oganov AM, et al.: Fidaxomicin for Clostridium difficile-associated diarrhoea: epidemiological method for estimation of warranted price. Clin Drug Investig. 2012, 32:e17-24. 10.2165/11633500-000000000-00000

45. Gallagher JC, Reilly JP, Navalkele B, et al.: Clinical and economic benefits of fidaxomicin compared to vancomycin for Clostridium difficile infection. Antimicrob Agents Chemother. 2015, 59:7007-10. 10.1128/AAC.00939-15

46. Rubio-Terrés C, Cobo Reinoso J, Grau Cerrato S, et al.: Economic assessment of fidaxomicin for the treatment of Clostridium difficile infection (CDI) in special populations (patients with cancer, concomitant antibiotic treatment or renal impairment) in Spain. Eur J Clin Microbiol Infect Dis. 2015, 34:2213-23. 10.1007/s10096-015-2472-0

47. Reveles KR, Backo JL, Corvino FA, et al.: Fidaxomicin versus vancomycin as a first-line treatment for Clostridium difficile-associated diarrhea in specific patient populations: a pharmacoeconomic evaluation. Pharmacotherapy. 2017, 37:1489-97. 10.1002/phar.2049

48. Le P, Nghiem VT, Mullen PD, Deshpande A: Cost-effectiveness of competing treatment strategies for Clostridium difficile infection: a systematic review. Infect Control Hosp Epidemiol. 2018, 39:412-24. 10.1017/ice.2017.303

49. Wagner M, Lavoie L, Goetghebeur M: Clinical and economic consequences of vancomycin and fidaxomicin for the treatment of Clostridium difficile infection in Canada. Can J Infect Dis Med Microbiol. 2014, 25:8794. $10.1155 / 2014 / 793532$ 